\title{
THE LAGGED EFFECT OF AIR POLLUTION ON HUMAN EOSINOPHILS: A DISTRIBUTED LAG NON-LINEAR MODEL
}

\section{ZHAOJUN DING ${ }^{1}$, ZHEN XIE ${ }^{2,3}$, YANG SU $^{3,4}$, JIYING QI ${ }^{1}$, and BIN CUI ${ }^{1}$}

${ }^{1}$ Shanghai Jiao Tong University School of Medicine, Shanghai, China

Shanghai Clinical Center for Endocrine and Metabolic Diseases, Shanghai Institute of Endocrine and Metabolic Diseases, Ruijin Hospital

${ }^{2}$ University of Electronic Science and Technology of China, Chengdu, China

Department of Dermatology, Sichuan Provincial People's Hospital

${ }^{3}$ Chinese Academy of Sciences Sichuan Translational Medicine Research Hospital, Chengdu, China

${ }^{4}$ University of Electronic Science and Technology of China, Chengdu, China

Clinical Laboratory, Sichuan Provincial People's Hospital

\begin{abstract}
Objectives: The aim of this study was to determine the lag between exposure to air pollutants and changes in human eosinophil counts. Material and Methods: This was a retrospective study employing 246425 physical examination records dated December 2013 - December 2016 from Chengdu, China. The authors determined the prevalence of individuals with eosinophil counts above the normal reference range each day. A distributed lag non-linear model was used to evaluate the lagged effect of each air pollutant on eosinophil counts. The lagged effects of each air pollutant were counted and presented with smoothing splines. Results: The effects of air pollutants such as particulate matter $\left(\mathrm{PM}_{2.5}\right.$, aerodynamic diameters $<2.5 \mu \mathrm{m}$; $\mathrm{PM}_{10}$, aerodynamic diameters $\left.<10 \mu \mathrm{m}\right)$, nitrogen dioxide $\left(\mathrm{NO}_{2}\right)$ and ozone $\left(\mathrm{O}_{3}\right)$ were evaluated. In women, the effects of $\mathrm{PM}{ }_{25}(\mathrm{RR}=1.154$, 95\% CI: $1.061-1.255)$ and $\mathrm{PM}_{10}(\mathrm{RR}=1.309,95 \% \mathrm{CI}$ : 1.130-1.517) reached the maximum values on lag day 0 . In men, there was no significant effect of $\mathrm{PM}_{2.5}$, but significant effects of $\mathrm{PM}_{10}$ were found for lag days 20-28. The effects of $\mathrm{NO}_{2}$ and $\mathrm{O}_{3}$ on eosinophils were not statistically significant for either gender. Conclusions: The air pollutants of $\mathrm{PM}_{10}$ have a significant effect on human eosinophils for both women and men, but with different temporal patterns, with women showing a lag of 0-5 days and men showing a lag of 20-28 days. In addition, $\mathrm{PM}_{25}$ was significant for women with a lag of 0-3 days but it was not significant for men. Int J Occup Med Environ Health. 2020;33(3):299-310
\end{abstract}

Key words:

air pollution, gender difference, eosinophils, real-world data, lagged effect, distributed lag non-linear model

\section{INTRODUCTION}

According to the World Health Organization (WHO) report of 2018, 9 out of 10 people now breathe polluted air, which kills 7 million people every year [1]. With the rapid development of industrialization, air pollution has be- come one of the most important environmental problems in China. The Chinese Department of Environmental Protection considered particulate matter $\left(\mathrm{PM}_{2.5}\right.$, aerodynamic diameters $<2.5 \mu \mathrm{m} ; \mathrm{PM}_{10}$, aerodynamic diameters $<10 \mu \mathrm{m})$, sulfur dioxide $\left(\mathrm{SO}_{2}\right)$, nitrogen dioxide $\left(\mathrm{NO}_{2}\right)$,

Funding: this study was supported by the National Key R\&D Program of China (grant No. 2018 YFC1314802 entitled "Data analysis and information integration based on information platform," grant manager: Prof. Bin Cui).

Received: August 16, 2019. Accepted: January 23, 2020.

Corresponding author: Bin Cui, Shanghai Jiao Tong University School of Medicine, Shanghai Clinical Center for Endocrine and Metabolic Diseases, Shanghai Institute of Endocrine and Metabolic Diseases, Ruijin Hospital, 197 Ruijin Er Lu, Shanghai 200025, China (e-mail: cb11302@rjh.com.cn). 
carbon monoxide $(\mathrm{CO})$ and ozone $\left(\mathrm{O}_{3}\right)$ as the primary air pollutants and included them in the latest China's Ambient Air Quality Standard (GB 3095-2012) in 2012 [2]. The 24-h mean threshold values of $\mathrm{PM}_{2.5}, \mathrm{PM}_{10}, \mathrm{SO}_{2}, \mathrm{CO}$ and $\mathrm{O}_{3}$ in $\mathrm{GB} 3095-2012$ are higher than the 2005 WHO air quality suggested values.

Previous studies have confirmed that exposure to air pollutants would lead to the development of cardiovascular diseases, lung diseases, and immunity-related diseases such as allergic rhinitis, childhood asthma, and atopic dermatitis [3-8]. Epstein et al. [9] evaluated the relationship between exposure to traffic pollutants and asthma control, and found that traffic pollutants increased eosinophilic inflammation in older adults with poorly controlled asthma. Meanwhile, other authors reported that eosinophils increased with exposure to air pollutants [10-12]. On the other hand, Fauzie and Venkataramana [13] performed animal experiments with albino mice exposed to traffic-related air pollutants, and the results showed that eosinophils were significantly reduced.

However, some controversy remains about the impact of air pollution on eosinophils. One study of the association between eosinophilic activation and air pollution showed no significant associations between the number of eosinophils and $\mathrm{PM}_{2.5}$ or $\mathrm{NO}_{2}$, which did not show the cumulative effect of air pollution [14].

Stimulated by the above studies, physical examination records, and air pollutant and meteorological data are used in this study to determine the effect of air pollution on human eosinophil counts and clarify whether there is a lagged effect of air pollution on human eosinophils.

\section{MATERIAL AND METHODS}

\section{Study area}

Chengdu is located in the western part of the Sichuan Province, geographically situated between 102 54' E $104^{\circ} 53^{\prime} \mathrm{E}$ and $30^{\circ} 05^{\prime} \mathrm{N} \sim 31^{\circ} 26^{\prime} \mathrm{N}$. In 2016, the city's land area was $14335 \mathrm{~km}^{2}$, and there were 11 urban built-up ar- eas totaling about $4000 \mathrm{~km}^{2}$. Due to high traffic density and special basin topography, the urban area suffers from a high concentration of air pollutants $[15,16]$.

\section{Study population}

This is a population-based study with a retrospective analysis of real-world data for the period of December 2013 - December 2016. The data were extracted from the records of men and women sent by their employers to receive annual physical examinations at the Physical Examination Center of the Sichuan Provincial People's Hospital. The biochemical tests of all subjects were carried out in the Department of Clinical Laboratory in the Sichuan Provincial People's Hospital immediately after sample collection. The normal reference range for serum eosinophil counts, as provided by the clinical laboratory, is $0.02-0.52 \times 10^{9} / 1$.

Initially 275088 records were included. In order to eliminate abnormal interference, the following exclusion criteria were used:

- incomplete data, for example, the examination time, specific age and gender, and examination results are missing;

- individuals aged $<18$ or $\geq 65$ years;

- eosinophils < $<.02 \times 10^{9} /$;

- diagnosis of cancer;

- dates with $<15$ physical examination records.

Following these exclusions, 246425 records remained. The validity and reliability of the physical examination data were ensured through a stringent quality assurance and quality control program by the Sichuan Provincial People's Hospital. The Ethics Committee in the Sichuan Provincial People's Hospital gave its permission for this study.

\section{Air pollutants and meteorological data}

All air pollutant and meteorological data were received from the China National Environmental Monitoring Center [17]. The meteorological data, including 
the mean value of daily temperature (DT), relative humidity (RH), daily average values of $\mathrm{PM}_{2.5}, \mathrm{PM}_{10}, \mathrm{SO}_{2}$, $\mathrm{NO}_{2}, \mathrm{CO}$ concentration, and 8-h maximum daily sliding average of $\mathrm{O}_{3}$ concentration in Chengdu, were all recorded throughout the study period. The methods for air pollutant and meteorological data collection, including time resolution and instrumentation details, were as described previously [16].

\section{Statistical analysis}

The authors assumed that the impact of air pollutants on the human body was not significantly effective beneath a certain threshold. That threshold was selected in accordance with China's Ambient Air Pollution Standards (GB 3095-2012) [2]. A distributed lag non-linear model (DLNM) was used to evaluate the lagged effects of each air pollutant [18]. The authors counted the number of physical examination records per day with eosinophil counts exceeding the upper limit of the normal reference range $\left(0.52 \times 10^{9} / 1\right)$ as the daily prevalence.

Due to the observed dispersion of data, the authors used the quasi-Poisson regression to fit them. The DLNM equation was as follows:

$$
\begin{gathered}
\log \left(\mathrm{E}_{\left.\left(\mathrm{Y}_{\mathrm{t}}\right)\right)}=\alpha+\mathrm{cb}\left(\mathrm{X}_{\mathrm{t}} \mathrm{l}, \mathrm{thr}\right)+\mathrm{ns}(\text { time, } \mathrm{df})+\right. \\
\mathrm{ns}(\mathrm{DT}, \mathrm{df})+\mathrm{ns}(\mathrm{RH}, \mathrm{df})+\text { DOW }
\end{gathered}
$$

where:

$\mathrm{Y}_{\mathrm{t}}$ - the event rates of the parts per 10000 by every day in the study period;

$\mathrm{E}\left(\left(\mathrm{Y}_{\mathrm{t}}\right)\right)$ - the expected value for $\mathrm{Y}_{\mathrm{t}}$;

$\alpha$ - the intercept;

$\mathrm{cb}$ - the cross-basis function which can be depicted as a 2-dimen-

sional space of functions describing simultaneously the shape of the relationship along a single air pollutant and its distributed lag effects [19];

$\mathrm{X}_{\mathrm{t}}$ - the daily average concentration of each air pollutant $\left(\mathrm{PM}_{2.5}\right.$, $\mathrm{PM}_{10}, \mathrm{SO}_{2}, \mathrm{NO}_{2}, \mathrm{CO}$ and $\mathrm{O}_{3}$ ), which depicted a linear effect on human eosinophils (the lag effect of $X_{t}$ was depicted using a third-degree polynomial function);

1 - the number of lag days for the effect of each air pollutant;

thr - the threshold of each air pollutant effect;

ns - the natural spline function which was used to smoothen the time trend effects of a long-term character, daily temperature and relative humidity;

time was used to control the time trend effects of a long-term character;

$\mathrm{df}$ - the degree of freedom;

DT - daily temperature;

$\mathrm{RH}$ - relative humidity;

DOW - the day of the week which was used to control the week effects.

The authors chose the appropriate df according to the Partial Autocorrelation Function (PACF), and the calculation method was as reported previously [20]. The maximum permitted lag was 35 days, which was determined by the survival time of eosinophils and a smaller value of the quasi-Akaike information criterion (QAIC) [21]. Relative risk (RR) values with their respective $95 \%$ confidence intervals $(95 \% \mathrm{CI})$ were used to show the effect of each air pollutant with a $10 \mu \mathrm{g} / \mathrm{m}^{3}$ increase in concentration.

Data processing and statistical analyses were performed using "splines" and "dlnm" packages of R software (version 3.5.2) [18,22].

\section{RESULTS}

\section{Basic data description}

Table 1 shows the basic information derived from physical examination records. After excluding extreme values and filtering data according to the exclusion criteria, 246425 physical examination records were included in this study. Among these, 4546 records showed eosinophil counts exceeding $0.52 \times 10^{9} / 1$, of which 3164 concerned men and 1382 women. The prevalence in men was significantly 
Table 1. Characteristics of the medical records of 246425 participants by gender at the Physical Examination Center of the Sichuan Provincial People's Hospital in Chengdu, China (December 2, 2013 - December 2, 2016)

\begin{tabular}{|c|c|c|c|}
\hline \multirow{2}{*}{ Variable } & \multicolumn{3}{|c|}{$\begin{array}{l}\text { Participants } \\
(\mathrm{N}=246425)\end{array}$} \\
\hline & total & $\begin{array}{c}\text { men } \\
(\mathrm{N}=136030)\end{array}$ & $\begin{array}{c}\text { women } \\
(\mathrm{N}=110395)\end{array}$ \\
\hline \multicolumn{4}{|l|}{ Records } \\
\hline physical examination [n] & 246425 & 136030 & 110395 \\
\hline daily $(\mathrm{Me}(25-75 \%))$ & $266(199-348)$ & $145(104-193)$ & $120(89-151)$ \\
\hline Age [years] $(\mathrm{M} \pm \mathrm{SD})$ & $40.3 \pm 11.20$ & $40.7 \pm 11.11$ & $39.8 \pm 11.42$ \\
\hline $\mathrm{BMI}\left[\mathrm{kg} / \mathrm{m}^{2}\right](\mathrm{M} \pm \mathrm{SD})$ & $23.3 \pm 3.40$ & $24.3 \pm 3.2$ & $22.0 \pm 3.10$ \\
\hline \multicolumn{4}{|l|}{ Blood cell counts } \\
\hline erythrocytes $\left[10^{12} / 1\right](\mathrm{M} \pm \mathrm{SD})$ & $4.86 \pm 0.55$ & $5.16 \pm 0.48$ & $4.49 \pm 0.40$ \\
\hline leukocytes $\left[10^{9} / 1\right](\mathrm{Me}(25-75 \%))$ & $6.02(5.012-7.09)$ & $6.27(5.37-7.35)$ & $5.72(4.86-6.73)$ \\
\hline neutrophils $\left[10^{9} / 1\right](\mathrm{Me}(25-75 \%))$ & $3.40(2.77-4.17)$ & $3.50(2.88-4.27)$ & $3.27(2.64-4.04)$ \\
\hline eosinophils $\left[10^{9} / 1\right](\mathrm{Me}(25-75 \%))$ & $0.11(0.07-0.18)$ & $0.13(0.08-0.21)$ & $0.09(0.06-0.15)$ \\
\hline basophils $\left[10^{9} / 1\right](\mathrm{Me}(25-75 \%))$ & $0.032(0.021-0.048)$ & $0.037(0.022-0.005)$ & $0.03(0.02-0.042)$ \\
\hline lymphocytes $\left[10^{9} / 1\right](\mathrm{Me}(25-75 \%))$ & $1.95(1.60-2.37)$ & $2.04(1.67-2.47)$ & $1.85(1.53-2.23)$ \\
\hline monocytes [109/1] $(\mathrm{M} \pm \mathrm{SD})$ & $0.43 \pm 0.14$ & $0.46 \pm 0.15$ & $0.38 \pm 0.12$ \\
\hline
\end{tabular}

higher than in women according to the Wilcoxon signedrank test $(0.13$ vs. $0.09, \mathrm{p}<0.01)$.

\section{Variable description}

The daily average values of $\mathrm{PM}_{2.5}, \mathrm{PM}_{10}, \mathrm{SO}_{2}, \mathrm{NO}_{2}, \mathrm{CO}$ concentration, the 8-h maximum daily sliding average of $\mathrm{O}_{3}$ concentration, and the daily prevalence of eosinophil counts exceeding the upper limit of the reference range are listed in Table 2 . The daily average concentrations of $\mathrm{PM}_{2.5}$ and $\mathrm{PM}_{10}$ for 330 and 234 days, respectively, were higher than the standard values stipulated in China's Ambient Air Pollution Standards. The values of $\mathrm{NO}_{2}$ and $\mathrm{O}_{3}$ exceeded the standard values for 64 and 132 days, respectively. However, the values of $\mathrm{SO}_{2}$ and $\mathrm{CO}$ were always under the standard values in the study period, and thus DLNM could not evaluate their effects. Meteorological data, including temperature and relative humidity, were dispersed evenly.

\section{Air pollution effects}

The effects of 4 pollutants $\left(\mathrm{PM}_{2.5}, \mathrm{PM}_{10}, \mathrm{NO}_{2}\right.$ and $\left.\mathrm{O}_{3}\right)$ on men and women are shown in Figure 1. Of these pollutants, $\mathrm{PM}_{2.5}$ and $\mathrm{PM}_{10}$ had a greater effect on eosinophils in men than in women, and showed a distinct lagged effect in men (Figure 1a and Figure 1b vs. Figure 1e and Figure 1f).

In women, the effects of $\mathrm{PM}_{2.5}$ (RR: $1.154,95 \% \mathrm{CI}$ : 1.061-1.255) and $\mathrm{PM}_{10}$ (RR: 1.309, 95\% CI: 1.130-1.517) reached the maximum value on lag day 0 , then decreased as the lag time increased (Figure 1e and Figure 1f). More specifically, $\mathrm{PM}_{2.5}$ and $\mathrm{PM}_{10}$ produced effects in women on lag days $0-3$ and lag days $0-5$, respectively. In men, the results for $\mathrm{PM}_{2.5}$ were not significant. However, significant results were found for $\mathrm{PM}_{10}$ on lag days 20-28 (RR: 1.072, 95\% CI: 1.005-1.143), with the maximum value occurring on lag day 24.

The other air pollutants, $\mathrm{NO}_{2}$ and $\mathrm{O}_{3}$, had no significant effect on eosinophil counts in men (Figure 1c and Figure 1d) 
Table 2. Summary statistics of daily prevalence, air pollutants and weather factors at the Physical Examination Center of the Sichuan Provincial People's Hospital in Chengdu, China (December 2, 2013 - December 2, 2016)

\begin{tabular}{lccc}
\hline \multicolumn{1}{c}{ Exposure variable } & Me $(25-75 \%)$ & Min. & Max \\
\hline Daily incidence rate & & & 938 \\
total & $176(118-245.2)$ & 0 & 1250 \\
men & $220(132-321)$ & 0 & 1667 \\
women & $109(0-190)$ & 0 & \\
Daily pollutant concentration & & & 396 \\
$\mathrm{PM}_{2.5}\left[\mu \mathrm{gg} / \mathrm{m}^{3}\right]^{\mathrm{a}}$ & $53(36-83)$ & 10 & 562 \\
$\mathrm{PM}_{10}\left[\mu \mathrm{g} / \mathrm{m}^{3}\right]^{\mathrm{b}}$ & $91(63-140)$ & 16 & 61 \\
$\mathrm{SO}_{2}\left[\mu \mathrm{g} / \mathrm{m}^{3}\right]^{\mathrm{c}}$ & $14(11-20)$ & 4 & 118 \\
$\mathrm{NO}_{2}\left[\mu \mathrm{g} / \mathrm{m}^{3}\right]^{\mathrm{d}}$ & $50(41-62)$ & 15 & 293 \\
$\mathrm{O}_{3}\left[\mu \mathrm{g} / \mathrm{m}^{3}\right]^{\mathrm{e}}$ & $82(50-127)$ & 7 & 2.6 \\
$\mathrm{CO}\left[\mathrm{mg} / \mathrm{m}^{3}\right]^{\mathrm{f}}$ & $1(0.9-1.3)$ & 0.4 & 32 \\
Weather factor & & & 100 \\
temperature $\left[{ }^{\circ} \mathrm{C}\right]$ & $20(12-24)$ & 2 & 27 \\
relative humidity $[\%]$ & $73(66-82)$ & & \\
\hline
\end{tabular}

a Pollution days: 330 above the standard value, 767 under the standard value.

${ }^{b}$ Pollution days: 234 above the standard value, 863 under the standard value.

c Pollution days: 0 above the standard value, 1097 under the standard value.

d Pollution days: 64 above the standard value, 1033 under the standard value.

e Pollution days: 132 above the standard value, 965 under the standard value.

${ }^{\text {f }}$ Pollution days: 0 above the standard value, 1097 under the standard value.

or women (Figure 1g and Figure 1h). More data can be found in Table 3.

\section{DISCUSSION}

Clinically, human eosinophils can be used to indicate the degree of immune response to a disease [23,24]. Eosinophil counts are especially good indicators for hypersensitivity pneumonitis, eczema, and helminth infections. Here, the authors used eosinophil counts as a biomarker to show the harmful effects of air pollution. The effect of exposure to air pollution on the human body is usually a lagged effect that is not limited to the period when it is observed [17,18]. Therefore, DLNMs were used to demonstrate the effects of 4 pollutants $\left(\mathrm{PM}_{2.5}\right.$, $\mathrm{PM}_{10}, \mathrm{NO}_{2}$ and $\mathrm{O}_{3}$ ) on eosinophil counts. To date, DLNMs have been widely used to discover lagged effects of exposure (especially for air pollution) on outcomes [25-27].
For both men and women, $\mathrm{PM}_{2.5}$ and $\mathrm{PM}_{10}$ had the largest effects on eosinophil counts. In 2010, Sehlstedt et al. [12] took 15 healthy subjects, exposed them to an average particulate matter concentration of $270 \mu \mathrm{g} / \mathrm{m}^{3}$ or filtered air for $1 \mathrm{~h}$, and found that particulate matter exposure increased the number of bronchoalveolar lavage eosinophils in these healthy subjects. Moreover, Carlsten et al. [10] recruited 18 blinded atopic volunteers and had them inhale $300 \mathrm{mg} \mathrm{PM}{ }_{2.5} / \mathrm{m}^{3}$ of diesel exhaust; the results showed that airway eosinophils increased in atopic patients at environmentally relevant concentrations of $\mathrm{PM}_{2.5}$. In the 2 studies mentioned above, the effects of air pollution on gender were not evaluated, and neither were lagged effects. A separate study reported no significant association between the number of eosinophils and exposure to $\mathrm{PM}_{2.5}$ in 521 children [14]. However, this study used adults aged 

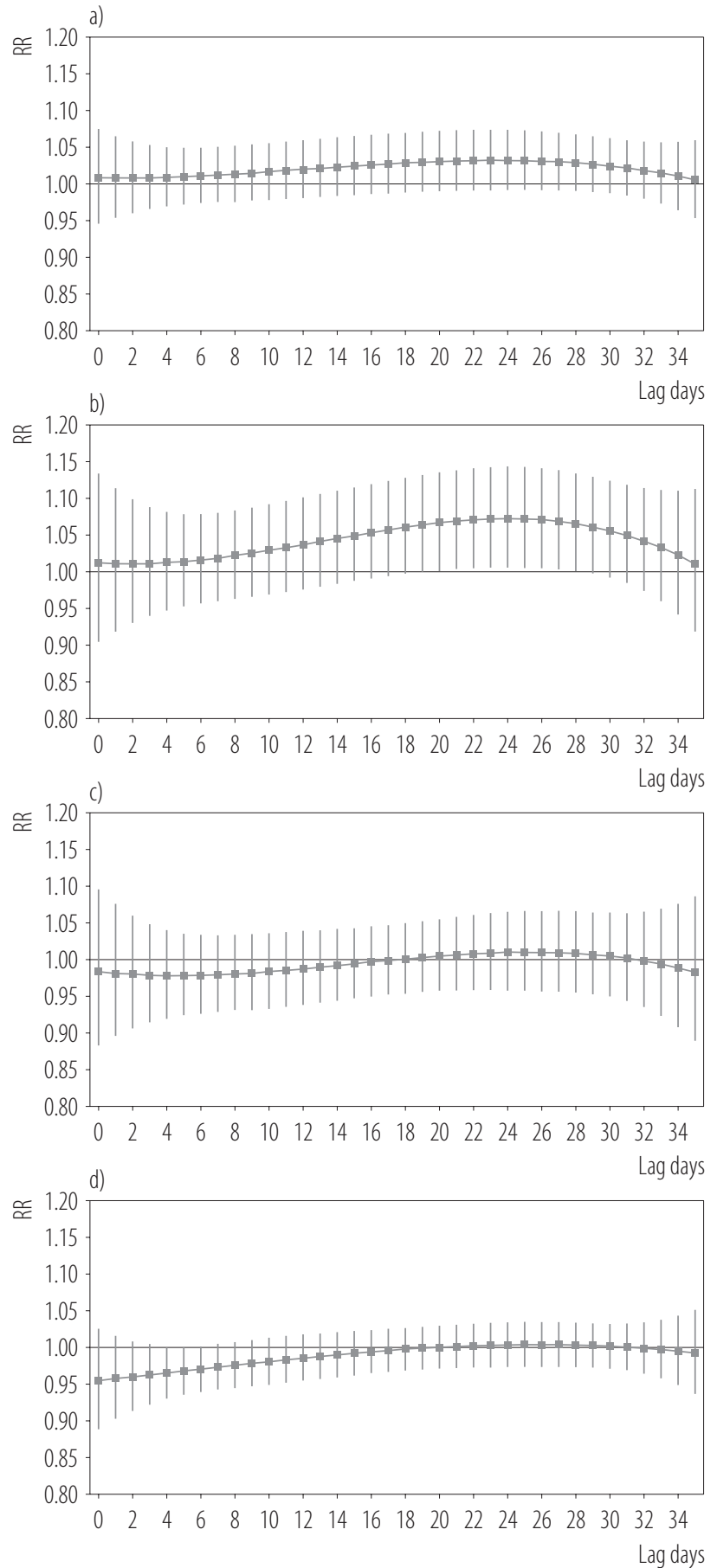
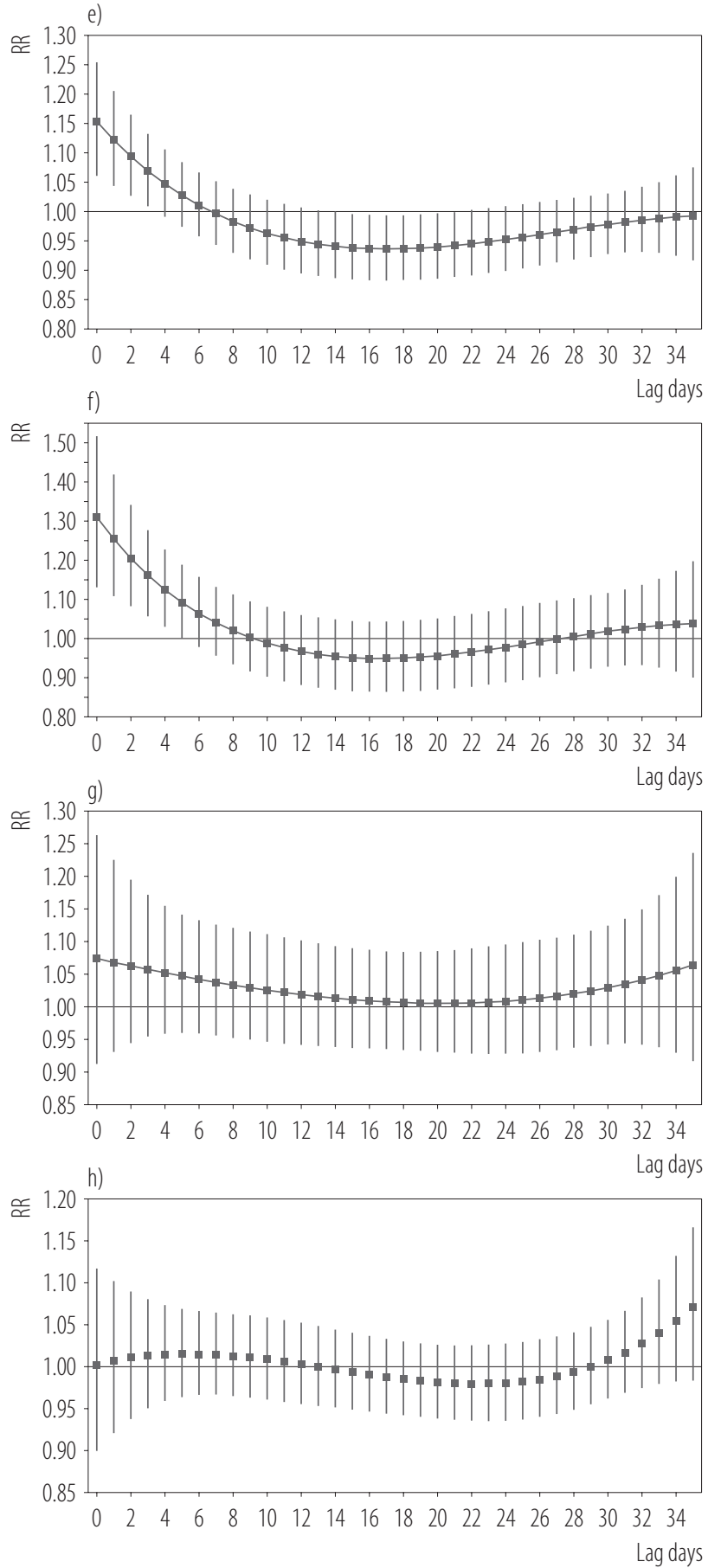

Vertical bars - 95\% CI.

$\mathrm{NO}_{2}$ - nitrogen dioxide; $\mathrm{O}_{3}$ - ozone; $\mathrm{PM}_{2.5}$ - particulate matter with an aerodynamic diameter of $<2.5 \mu \mathrm{m} ; \mathrm{PM}_{10}$ - particulate matter with an aerodynamic diameter of $<10 \mu \mathrm{m}$.

Figure 1. The lagged effect of air pollution on eosinophils in a-d) men and e-h) women - splines showed changes in relative risk (RR) values caused by a $10 \mu \mathrm{g} / \mathrm{m}^{3}$ increase in the average daily concentration of a) and e) $\mathrm{PM}_{2,5}$, b) and f) $\mathrm{PM}_{10}$, c) and g) $\mathrm{NO}_{2}$, and the 8-h max daily sliding average of d) and h) $\mathrm{O}_{3}$ during 35 lag days 


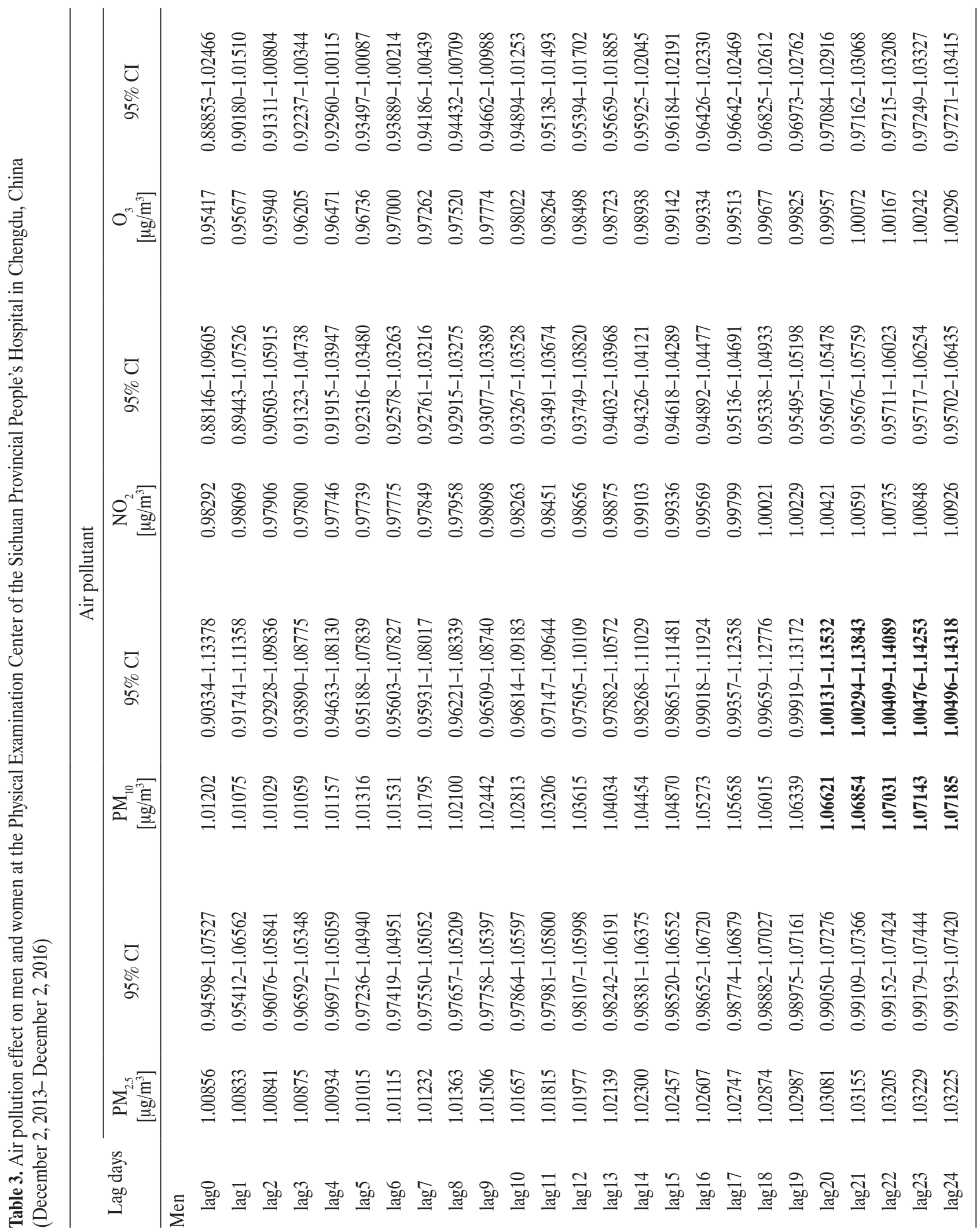




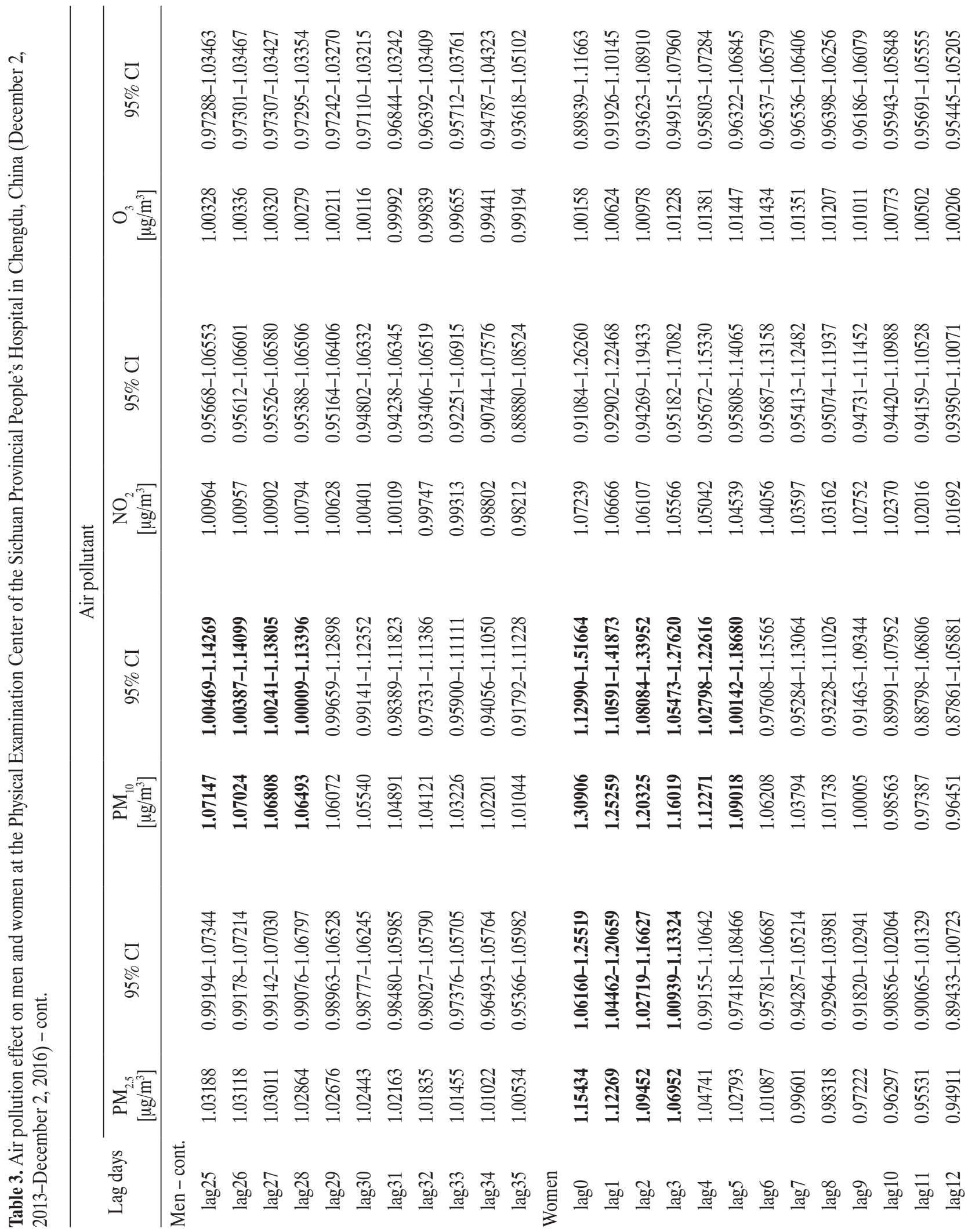




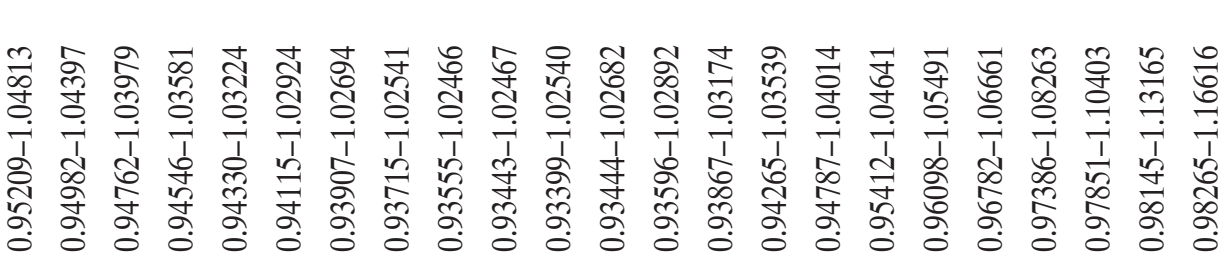

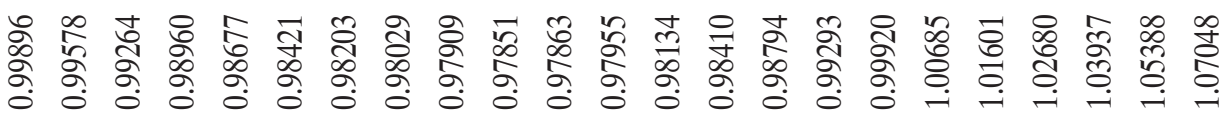

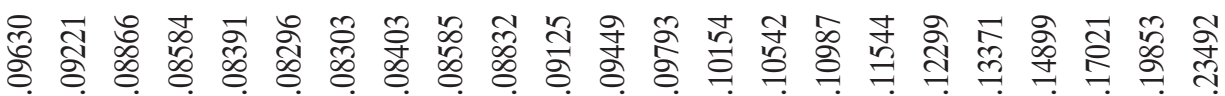

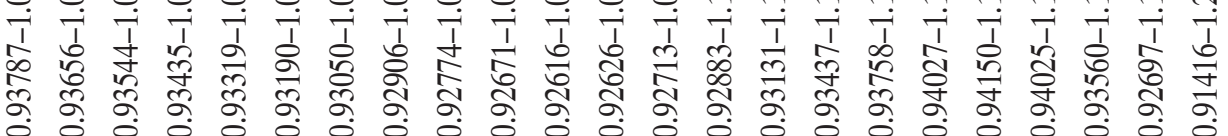

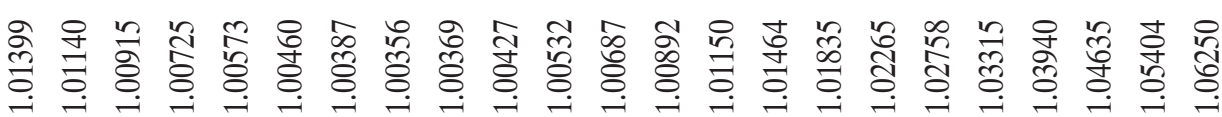
휴 \&

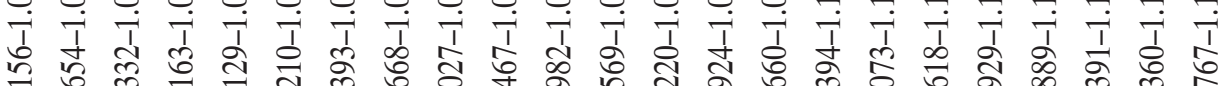

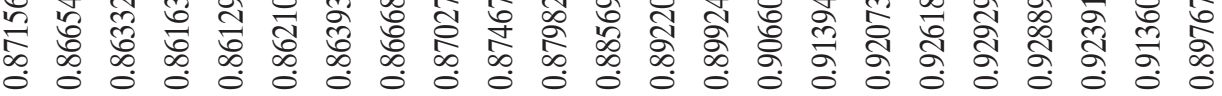

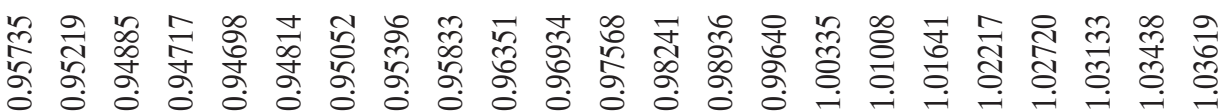

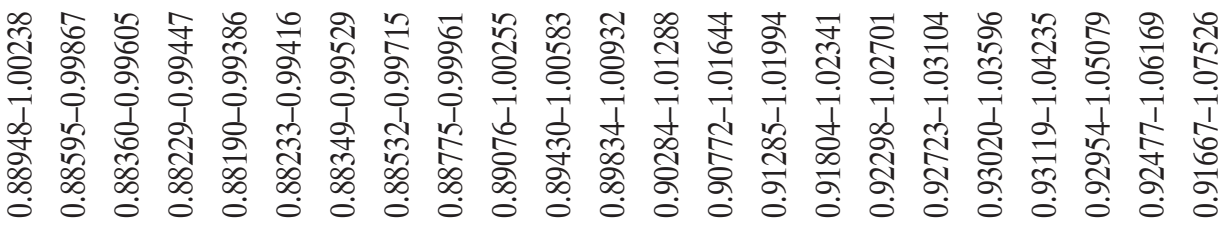

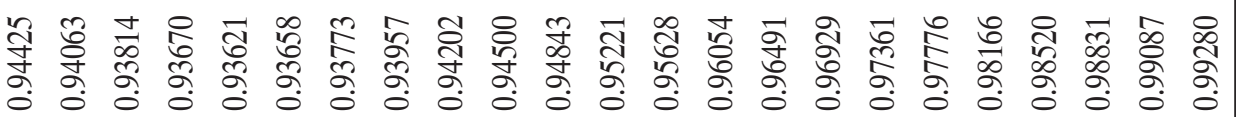

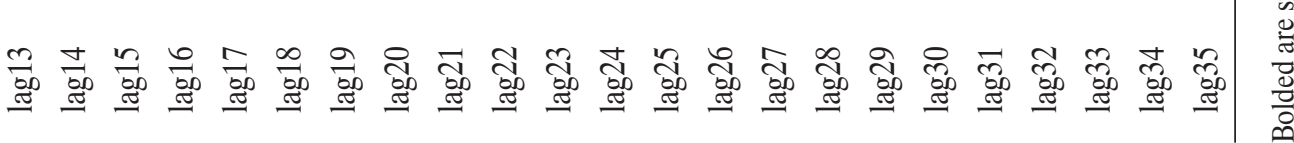


18-65, whose immune functions differed from those of children.

The results presented in this study demonstrate that the effects of air pollution on eosinophils differed between men and women. Many studies have reported that the innate immunity of women, both humoral and cellular, is stronger than that of men [28-30]. Estrogen promotes the development of the T helper 2 (Th2) response and stimulates the secretion of proinflammatory cytokines (IL-4, IL-5 and IL-10) [29]. Of note is the fact that IL-5 can help recruit eosinophils from the blood to inflammatory foci $[29,31]$. In this study, the eosinophil responses to $\mathrm{PM}_{2.5}$ and $\mathrm{PM}_{10}$ were different in men and women, as shown in the Figures 1a and 1b, and Figures 1e and 1f. The maximal effect was on the first day of exposure in women, then it gradually decreased within 2-3 weeks after exposure. On the other hand, men were less affected by $\mathrm{PM}_{2.5}$ and $\mathrm{PM}_{10}$ during the first few days of exposure, but then showed increased effects as the number of lag days increased, reaching maximum values in 3-4 weeks. This study confirms a genderdependent difference in immune function, with eosinophils in women being more involved than in men.

The authors acknowledge some limitations of their study. First, they did not include the subjects' histories of medication, allergy, pregnancy, menopause, or smoking, all of which may influence eosinophil counts. In addition, occupational and lifestyle factors may lead to some difference in effective exposure to ambient air pollution between men and women. Fortunately, the large cohort of physical examination records, which was used in this study, would reduce the deviation of various factors, enabling the authors to clarify the associations between air pollution, eosinophils, and gender.

\section{CONCLUSIONS}

The air pollutants of $\mathrm{PM}_{10}$ have a significant effect on human eosinophils for both women and men, but with different temporal patterns, with women showing a lag of 0-5 days and men showing a lag of 20-28 days. Notably, $\mathrm{PM}_{2.5}$ was significant for women with a lag of 0-3 days while it was not significant for men.

\section{ACKNOWLEDGMENTS}

Zhaojun Ding and Zhen Xie contributed equally to this work.

\section{REFERENCES}

1. World Health Organisation [Internet]. Geneva: The Organization; 2019 [cited 2019 Jul 5]. 9 Out of 10 People Worldwide Breathe Polluted Air, But More Countries Are Taking Action. Available from: https://www.who.int/news-room/detail/ 02-05-2018-9-out-of-10-people-worldwide-breathe-pollutedair-but-more-countries-are-taking-action.

2. Muller CO, Yu H, Zhu B. Ambient Air Quality in China: The Impact of Particulate and Gaseous Pollutants on IAQ. Procedia Engineering. 2015;121(1):582-9, https://doi.org/10.1016/j. proeng.2015.08.1037.

3. Ahn K. The role of air pollutants in atopic dermatitis. J Allergy Clin Immunol. 2014;134 (5):993-9, https://doi.org/10.1016/j. jaci.2014.09.023.

4. Brook RD, Newby DE, Rajagopalan S. Air Pollution and Cardiometabolic Disease: An Update and Call for Clinical Trials. Am J Hypertens. 2018;31(1):1-10, https://doi.org/10.1093/ajh/ hpx109.

5. Cecchi L, D'Amato G, Annesi-Maesano I. External exposome and allergic respiratory and skin diseases. J Allergy Clin Immunol. 2018;141(3):846-57, https://doi.org/10.1016/j. jaci.2018.01.016.

6. Khreis H, Kelly C, Tate J, Parslow R, Lucas K, Nieuwenhuijsen $\mathrm{M}$. Exposure to traffic-related air pollution and risk of development of childhood asthma: A systematic review and meta-analysis. Environ Int. 2017,100:1-31, https://doi. org/10.1016/j.envint.2016.11.012.

7. Norbäck D, Lu C, Zhang Y, Li B, Zhao Z, Huang C, et al. Sources of indoor particulate matter (PM) and outdoor air pollution in China in relation to asthma, wheeze, rhinitis and eczema among pre-school children: Synergistic effects 
between antibiotics use and PM 10 and second hand smoke. Environ Int. 2019;125:252-60, https://doi.org/10.1016/j.envint.2019.01.036.

8. Raaschou-Nielsen O, Andersen ZJ, Beelen R, Samoli E, Stafoggia M, Weinmayr G, et al. Air pollution and lung cancer incidence in 17 European cohorts: Prospective analyses from the European Study of Cohorts for Air Pollution Effects (ESCAPE). Lancet Oncol. 2013;14(9):813-22, https:// doi.org/10.1016/S1470-2045(13)70279-1.

9. Epstein TG, Kesavalu B, Bernstein CK, Ryan PH, Bernstein JA, Zimmermann N, et al. Chronic traffic pollution exposure is associated with eosinophilic, but not neutrophilic inflammation in older adult asthmatics. J Asthma. 2013;50(9): 983-9, https://doi.org/10.3109/02770903.2013.832293.

10. Carlsten C, Blomberg A, Pui M, Sandstrom T, Wong SW, Alexis N, et al. Diesel exhaust augments allergen-induced lower airway inflammation in allergic individuals: A controlled human exposure study. Thorax. 2016;71(1):35-44, https://doi.org/10.1136/thoraxjnl-2015-207399.

11. Fang Z, Huang C, Zhang J, Xie J, Dai S, Ge E, et al. Trafficrelated air pollution induces non-allergic eosinophilic airway inflammation and cough hypersensitivity in guinea-pigs. Clin Exp Allergy. 2019;49(3):366-77, https://doi.org/10.1111/cea. 13308.

12. Sehlstedt M, Behndig AF, Boman C, Blomberg A, Sandström T, Pourazar J. Airway inflammatory response to diesel exhaust generated at urban cycle running conditions. Inhal Toxicol. 2010;22(14):1144-50, https://doi.org/10.3109/08958 378.2010.529181.

13. Fauzie AK, Venkataramana GV. Exposure to organic and inorganic traffic-related air pollutants alters haematological and biochemical indices in albino mice Mus musculus. Int J Environ Health Res. 2019;13:1-17, https://doi.org/10.1080/ 09603123.2019.1577367.

14. Janssen NAH, Meer G, Brunekreef B. Exposure to air pollution from heavy traffic is associated with increased eosinophilic activation in Dutch schoolchildren. Epidemiol. 2004;15(4): 65-6, https://doi.org/10.1097/00001648-200407000-00160.
15. Liu R, Zeng J, Jiang X, Chen J, Gao X, Zhang L, et al. The relationship between airborne fine particle matter and emergency ambulance dispatches in a southwestern city in Chengdu, China. Environ Pollut. 2017;229:661-7, https:// doi.org/10.1016/j.envpol.2017.06.098.

16. Qiu H, Tan K, Long F, Wang L, Yu H, Deng R, et al. The burden of COPD morbidity attributable to the interaction between ambient air pollution and temperature in Chengdu, China. Int J Environ Res. 2018;15(15):492, https://doi. org/10.3390/ijerph15030492.

17. China National Environmental Monitoring Centre [Internet]. Beijing: The CNEMC; 2018 [cited 2018 Oct 12]. Available from: http://www.cnemc.cn.

18. Gasparrini A. Distributed Lag Linear and Non-Linear Models in R: The Package dlnm. J Stat Softw. 2011;43(8):1-20, https://doi.org/10.18637/jss.v043.i08.

19. Gasparrini A, Armstrong B, Kenward MG. Distributed lag non-linear models. Stat Med. 2010;29(21):2224-34, https:// doi.org/10.1002/sim.3940.

20. Peng RD, Dominici F, Louis TA. Model choice in time series studies of air pollution and mortality. J R Stat Soc Ser A Stat Soc. 2006;169:179-203, https://doi.org/10.1111/j.1467985X.2006.00410.x.

21. Xu HY, Fu X, Lee LKH, Ma S, Goh KT, Wong J, et al. Statistical Modeling Reveals the Effect of Absolute Humidity on Dengue in Singapore. PLoS Negl Trop Dis. 2014;8(5):2805, https://doi.org/10.1371/journal.pntd.0002805.

22. R Core Team, 2017. R: A Language and Environment for Statistical Computing. Vienna: R Foundation for Statistical Computing; 2013.

23. Becker S, Soukup, JM. Coarse $\left(\mathrm{PM}_{2.5-10}\right)$, fine $\left(\mathrm{PM}_{2.5}\right)$, and ultrafine air pollution particles induce/increase immune costimulatory receptors on human blood-derived monocytes but not on alveolar macrophages. J Toxicol Environ Heal - Part A. 2003;66(9):847-59, https://doi.org/10.1080/15287390306381.

24. Shamri R, Xenakis JJ, Spencer LA. Eosinophils in innate immunity: An evolving story. Cell Tissue Res. 2011;343(1): 57-83, https://doi.org/10.1007/s00441-010-1049-6. 
25. Allen, MJ, Sheridan SC. Mortality risks during extreme temperature events (ETEs) using a distributed lag non-linear model. Int J Biometeorol. 2015;62(1):57-67, https://doi. org/10.1007/s00484-015-1117-4.

26. Li A, Fan L, Xie L, Ren Y, Li L. Associations between air pollution, climate factors and outpatient visits for eczema in West China Hospital, Chengdu, south-western China: a time series analysis. J Eur Acad. Dermatology Venereol. 2018;32(3):486-94, https://doi.org/10.1111/jdv.14730.

27. Petkova EP, Gasparrini A, Kinney PL. Heat and mortality in new york city since the beginning of the 20th century. Epidemiology. 2014;25(4):554-60, https://doi.org/10.1097/ EDE.0000000000000123.

28. Chen W, Mempel M, Schober W, Behrendt H, Ring J. Gender difference, sex hormones, and immediate type hypersensitivity reactions. Allergy Eur J Allergy Clin Immunol. 2008;63(11):1418-27, https://doi.org/10.1111/j.13989995.2008.01880.x.

29. Ghazeeri G, Abdullah L, Abbas O. Immunological Differences in Women Compared with Men: Overview and Contributing Factors. Am J Reprod Immunol. 2011;66(3):163-9, https://doi.org/10.1111/j.1600-0897.2011.01052.x.

30. Hewagama A, Patel D, Yarlagadda S, Strickland FM, Richardson BC. Stronger inflammatory/cytotoxic T-cell response in women identified by microarray analysis. Genes Immun. 2009;10(5):509-16, https://doi.org/10.1038/gene. 2009.12.

31. Ravin KA, Loy M. The eosinophil in infection. Clin Rev Allergy Immunol. 2015;50(2):214-27, https://doi.org/10.1007/ s12016-015-8525-4.

This work is available in Open Access model and licensed under a Creative Commons Attribution-NonCommercial 3.0 Poland License - http://creativecommons.org/ licenses/by-nc/3.0/pl/deed.en. 